\title{
Sensitivity of High-Pitch Dual-Source Computed Tomography for the Detection of Anomalous Pulmonary Venous Connection in Infants
} Sensitivität der High-Pitch-Dual-Source-Computertomografie
zur Detektion von Pulmonalvenenfehlmündungen bei Säuglingen

Authors

Lennart Well ${ }^{1}$, Julius Matthias Weinrich ${ }^{1}$, Mathias Meyer ${ }^{1}$, Torben Kehl², Johannes Salamon , André Rüffer², Gerhard Adam¹, Jochen Herrmann ${ }^{3}$, Michael Groth ${ }^{3}$

Affiliations

1 Department of Diagnostic and Interventional Radiology and Nuclear Medicine, University Medical Center Hamburg-Eppendorf, Hamburg, Germany

2 Department of Pediatric Cardiology, University Heart \& Vascular Center Hamburg, Germany

3 Department of Diagnostic and Interventional Radiology and Nuclear Medicine, Department of Pediatric Radiology, University Medical Center Hamburg-Eppendorf, Hamburg, Germany

Key words

cardiac, CT-angiography, pediatric, pulmonary veins, radiation dose

received 12.06 .2020

accepted 29.09.2020

published online 10.12 .2020

Bibliography

Fortschr Röntgenstr 2021; 193: 551-558

DOI 10.1055/a-1290-6843

ISSN 1438-9029

(C) 2020. Thieme. All rights reserved.

Georg Thieme Verlag KG, Rüdigerstraße 14,

70469 Stuttgart, Germany

Correspondence

Dr. Lennart Well

Department of Diagnostic and Interventional Radiology Hamburg, University Medical Center Hamburg-Eppendorf, Martinistraße 52, 20251 Hamburg, Germany

Tel.: +49/015222816145

I.well@uke.de

\section{ABSTRACT}

Purpose To evaluate the sensitivity, specificity, and interobserver reliability of high-pitch dual-source computed tomography angiography (CTA) in the detection of anomalous pulmonary venous connection (APVC) in infants with congenital heart defects and to assess the associated radiation exposure.

Materials and Methods 78 pulmonary veins in 17 consecutively enrolled patients with congenital heart defects (6 fe- males; 11 males; median age: 6 days; range: 1-299 days) were retrospectively included in this study. All patients underwent high-pitch dual-source CTA of the chest at low tube voltages $(70 \mathrm{kV})$. APVC was evaluated independently by two radiologists. Sensitivity, specificity, positive (PPV) and negative predictive values (NPV), and interobserver agreement were determined. For standard of reference, one additional observer reviewed CT scans, echocardiography reports, clinical reports as well as surgical reports. In cases of disagreement the additional observer made the final decision based on all available information.

Results Detection of APVC with high-pitch dual-source CTA revealed a good sensitivity (91\%) and specificity (99\%), with PPV and NPV of $98 \%$ and $97 \%$. Interobserver agreement was almost perfect (Kappa $=0.84)$. The median DLP was $3.8 \mathrm{mGy}^{*} \mathrm{~cm}\left(\mathrm{IQR} 3.3-4.7 \mathrm{mGy}^{*} \mathrm{~cm}\right)$ and the median radiation dose was $0.33 \mathrm{mSv}$ (IQR $0.26-0.39 \mathrm{mSv}$ ).

Conclusion High-pitch dual-source CTA in infants with congenital heart defects allows for accurate and reliable assessment of APVC at a low radiation dose.

Key Points:

- High-pitch dual-source CTA enables detection of anomalous pulmonary vein connection with high sensitivity in infants.

- Interrater reliability in the detection of anomalous pulmonary vein connection with high-pitch dual-source CTA is almost perfect.

- Radiation dose of high-pitch dual-source CTA in the cardiac examination of infants is low.

\section{Citation Format}

- Well L, Weinrich JM, Meyer M et al. Sensitivity of High-Pitch Dual-Source Computed Tomography for the Detection of Anomalous Pulmonary Venous Connection in Infants. Fortschr Röntgenstr 2021; 193: 551-558

\section{ZUSAMMENFASSUNG}

Ziel Bewertung der Sensitivität, Spezifität und InterraterReliabilität der High-Pitch-Dual-Source-Computertomografie-Angiografie (CTA) in der Detektion von Pulmonalvenenfehlmündungen bei Säuglingen mit angeborenen Herzfehlern und Bewertung der damit verbundenen Strahlenbelastung. 
Material und Methoden In diese retrospektive Studie wurden 78 Lungenvenen aus 17 konsekutiv untersuchten Säuglingen mit angeborenen Herzfehlern eingeschlossen (6 Mädchen, 11 Jungen; Medianalter 6 Tage, Range 1-299 Tage). Bei allen Patienten wurde eine High-Pitch-Dual-Source-CTA des Thorax bei niedriger Röhrenspannung (70 kV) durchgeführt. Das Vorliegen von Pulmonalvenenfehlmündungen wurde von 2 Radiologen unabhängig voneinander bewertet. Sensitivität, Spezifität, positive (PPV) und negative prädiktive Vorhersagewerte (NPV) sowie die Interrater-Reliabilität wurden bestimmt. Als Referenzstandard diente die Kombination aus CT-Scans, Befunden der Echokardiografie, klinischen Berichten sowie Operationsberichten, die von einem erfahrenen Kinderradiologen in Zusammenschau ausgewertet wurden. Dieser entschied im Fall inkongruenter Befunde über die korrekte Interpretation.

Ergebnisse Die Detektion von Pulmonalvenenfehlmündungen mit der High-Pitch-Dual-Source-CTA gelang mit guter Sensitivität (91\%) und Spezifität (99\%), bei PPV und NPV von
$98 \%$ und $97 \%$. Die Interrater-Reliabilität war nahezu perfekt (Kappa =0,84). Der Median des DLP betrug 3,8 mGy* ${ }^{*} \mathrm{~cm}$ (IQR 3,3-4,7 mGy* $\mathrm{cm}$ ), die effektive Dosis betrug im Median 0,33 mSv (IQR 0,26-0,39 mSv).

Schlussfolgerung Die High-Pitch-Dual-Source-CTA bei Säuglingen mit angeborenen Herzfehlern ermöglicht eine genaue und zuverlässige Detektion von Lungenvenenfehlmündungen bei niedriger Strahlendosis.

\section{Kernaussagen:}

- Die High-Pitch-Dual-Source-CTA ermöglicht die Detektion von Pulmonalvenenfehlmündungen bei Säuglingen mit hoher Sensitivität.

- Die Interrater-Reliabilität bei der Erkennung von Pulmonalvenenfehlmündungen mit High-Pitch-Dual-Source-CTA ist hoch.

- Die Strahlendosis der High-Pitch-Dual-Source-CTA bei der kardialen Untersuchung von Säuglingen ist gering.

\section{Introduction}

Anomalous pulmonary venous connection (APVC) is a congenital cardiac defect which is present when one or more pulmonary veins drain into systemic veins. APVC can be further subdivided depending on the number of anomalous pulmonary veins returning to the left atrium. Total anomalous pulmonary venous connection (TAPVC) is the most severe form and is present if all pulmonary veins connect anomalously. TAPVC accounts for $1.5-2.6 \%$ of all congenital heart diseases [1], whereas partial anomalous venous connection (PAPVC) has been identified in $0.6-0.7 \%$ of patients in postmortem studies [2]. Complications of APVC include arrythmias and right-sided cardiac failure and more importantly, APVC can be associated with critical, complex congenital heart defects which become symptomatic within the first days of life and require surgical repair [3]. Timely presentation of these patients for surgical repair can lower the associated mortality [4]. However, accurate imaging is required to warrant precise pre-interventional planning and reduce intraoperative complications [5, 6].

For evaluation of heart defects in neonates, echocardiography is the established primary imaging modality with good spatial and temporal resolution. However, visualization of extracardiac structures can be limited [7]. Magnetic resonance imaging (MRI) offers the ability to quantify blood flow with the drawback of limited spatial resolution and high periprocedural efforts [8].

Development of high-pitch dual-source CTA now allows precise imaging of congenital heart defects in young children with high spatial resolution and 3D rendering with overall good image quality [9]. Additionally, improved dose reduction techniques allow visualization of cardiac defects in children at low radiation doses especially when compared to cardiac catheterization [10]. Previous studies have demonstrated good diagnostic accuracy of second-generation dual-source CT for the evaluation of APVC in pediatric patients $[7,11]$. However, an investigation regarding the diagnostic value of high-pitch third-generation dual-source CTA in the detection of APVC in infants has not been performed yet. We hypothesize that the diagnostic accuracy of high-pitch dual-source CTA for the evaluation of APVC in infants is high.

Therefore, the aim of this study was to evaluate the sensitivity, specificity, and interobserver reliability of high-pitch dual-source CTA in the detection of APVC in infants with congenital heart defects and to assess the associated radiation exposure.

\section{Materials and Methods}

\section{Study population}

The inclusion criteria for this study were referral for evaluation of congenital heart disease between April 2019 and May 2020 and age $\leq 12$ months. Out of 225 consecutive thoracic computed tomography examinations that were performed at our children's hospital during the observed time period, 17 patients ( 6 females and 11 males; median age: 6 days, range: 1-299 days) met the inclusion criteria. The most common indications for CT were evaluation of pulmonary vasculature $(5 / 17 ; 29.4 \%)$ and coarctation of the aorta $(4 / 17 ; 23.5 \%)$. None of the infants that matched the inclusion criteria were excluded from the investigated cohort.

This study complies with the Declaration of Helsinki. It has been approved by the local ethics committee and the requirement for informed consent was waived.

\section{CT technique}

The indication for CTA of the chest was in accordance with the "Consensus Recommendations of the German Radiology Society (DRG), the German Cardiac Society (DGK) and the German Society for Pediatric Cardiology (DGPK) on the Use of Cardiac Imaging 
with Computed Tomography and Magnetic Resonance Imaging" [12]. No examination was solely performed to evaluate APVC. A third-generation dual-source CT scanner (Somatom Force; Siemens Healthineers AG; Erlangen; Germany) was used for all examinations. CT scans were performed in the craniocaudal direction, ranging from the upper thoracic aperture to the posterior phrenicocostal angles. Patients were placed on the CT table in supine position with their arms elevated. If necessary, sedation was performed by the pediatric anesthetic team with special expertise in pediatric anesthesia ( $n=9 / 17 ; 52.9 \%)$. Contrast media was injected manually at a dose of $2.0 \mathrm{ml}$ per $\mathrm{kg}$ body weight (Imeron 300; Bracco Imaging; Konstanz; Germany) followed by a $6 \mathrm{ml}$ flush of sodium chloride $9 \mathrm{mg} / \mathrm{ml}$ ( $0.9 \%)$ solution prior to the examination. The start delay after completion of injection was $2 \mathrm{~s}$. Scans were performed with the following parameters using automatic exposure control (CareDose 4D; Siemens Healthineers AG; Erlangen; Germany): Tube voltage $70 \mathrm{kV}$; reference tube current time product per rotation $400 \mathrm{mAs}$; gantry rotation time $0.25 \mathrm{~s}$; detector collimation $2 \times 96 \times 0.6 \mathrm{~mm}$; slice collimation $192 \times 0.6 \mathrm{~mm}$ with z-flying focal spot technique; temporal resolution $111 \mathrm{~ms}$; pitch 1.9. Online tube current modulation was used. For reconstruction, the convolution kernel Bv36 (body vascular sharpness level) was employed and data were iteratively reconstructed (advanced modelled iterative reconstruction, ADMIRE 4). Slice thickness was $1 \mathrm{~mm}$ with an increment of $0.75 \mathrm{~mm}$.

\section{Image Analysis}

Datasets were analyzed by two radiologists in randomized order (6 years (LW) and 5 years (JMW) of radiology experience with 3 years (LW) and 2 years (JMW) of experience in cardiac and pediatric radiology). Readers were blinded to clinical information of patients, reports regarding echocardiography or surgery, and reason for referral. For image analysis, readers used the Centricity Universal Viewer (GE healthcare; Chalfont St Giles; GB). Multiplanar reformations (MPR) were created in $1 \mathrm{~mm}$ slices in axial, coronal, and sagittal planes. Additionally, 3D reformations of the heart were created from $1 \mathrm{~mm}$ axial slices with subsequent bone removal (IntelliSpace Portal; Philips Medical Systems DMC GmbH; Hamburg; Germany). The two observers rated the presence or absence of the left or right superior, middle, and inferior pulmonary vein, as well as the presence or absence of APC for each vein in each patient ( $n=78$ pulmonary veins).

For the standard of reference, a pediatric radiologist (MG) with 13 years of cardiac imaging experience reviewed all CT images, echocardiography reports, clinical reports and, if available, surgical reports $(n=9)$. If there was disagreement between the different modalities, the final decision was reached by the pediatric radiologist by combining all information. Moreover, pulmonary vein anatomy as described in the initial echocardiography report was compared with the standard of reference.

\section{Radiation dose}

Effective tube current, tube potential, total dose length product (DLP), volumetric CT dose index (CTDlvol), and scan length were recorded for all patients. Radiation exposure was assessed as volu- metric CT dose index (CTDIvol), referring to a $32 \mathrm{~cm}$ acrylic phantom. The effective dose (ED) was estimated as DLP*k, applying an individual linear interpolation of a conversion factor reported for chest $\mathrm{CT}$ in neonates $\left(\mathrm{k}_{0}=0.0823 \mathrm{mSv} / \mathrm{mGy}^{*} \mathrm{~cm}\right)$ and 1 -year-olds $\left(\mathrm{k}_{1}=0.0525 \mathrm{mSv} / \mathrm{mGy}^{*} \mathrm{~cm}\right)$ at $80 \mathrm{kV}$ as a function of days of life $[13,14]:$

$\mathrm{ED}=\mathrm{DLP} *\left(\mathrm{k}_{0}+\left((\mathrm{d} / 365) *\left(\mathrm{k}_{1}-\mathrm{k}_{0}\right)\right)\right.$

\section{Statistical analysis}

The sensitivity, specificity, positive predictive value, negative predictive value, and accuracy for CTA were calculated. Interobserver agreement was calculated using Cohen kappa statistics. The results were interpreted as follows: $<0.01$, poor or less than chance agreement; $0.01-0.20$, slight agreement; $0.21-0.40$, fair agreement; $0.41-0.60$, moderate agreement; $0.61-0.80$, substantial agreement; 0.81-0.99, almost perfect agreement [15]. For statistical analysis commercially available software tools were used (MedCalc for Windows, Mariakerke, Belgium and Excel, Microsoft Corporation, Redmond WA USA).

\section{Results}

APVC was present in 6/17 patients ( $35 \%$; 1 female; 5 males) with a total of $22 / 78(28 \%)$ anomalous draining pulmonary veins. Of the 22 identified anomalous draining pulmonary veins, 14 were of the right lung and 8 were of the left lung. Total anomalous venous connections (TAPVCs) were identified in 3 patients ( $\mathbf{F i g .} \mathbf{1}$ ) and partial anomalous venous connections (PAPVCs) were identified in 3 patients ( $\triangleright$ Fig. 2 ) [16].

In the initial echocardiography reports $5 / 6$ patients (83.3\%) with APVC were correctly identified. The pulmonary vein anatomy could not be visualized completely in two of these five patients. One patient with APVC was erroneously diagnosed as a correct pulmonary venous connection. In two patients without APVC, the pulmonary vein anatomy could not be sufficiently visualized. Nine out of eleven patients $(9 / 11 ; 81.8 \%)$ without APVC were categorized correctly with echocardiography. Additional information on patient characteristics, clinical symptoms, and associated congenital heart defects is given in $>$ Table 1 .

Detection of APVC with high-pitch dual-source CTA revealed an overall sensitivity of $91 \%$ (77-97\%) and a specificity of $99 \%$ (94-100\%). The overall PPV was $98 \%$ (86-100\%), the NPV was $97 \%$ (91-99\%). The overall accuracy was $97 \%$ with an accuracy of $97 \%$ for reader 1 and of $96 \%$ for reader 2 . - Table 2 summarizes the sensitivity, specificity, positive predictive value (PPV) as well as negative predictive value (NPV) overall and for both observers separately. False-positive detection of APVC occurred only one time in a case of PAPVC by observer 2. Furthermore, falsenegative detection of APVC was found two times in case of PAPVC by both observers. TAPVC was detected correctly in all cases. Interobserver agreement was almost perfect (Kappa $=0.84)$.

Radiation exposure of patients showed a median DLP of $3.8 \mathrm{mGy}^{*} \mathrm{~cm}\left(\mathrm{IQR} 3.3-4.7 \mathrm{mGy}^{*} \mathrm{~cm}\right)$ and an estimated median effective dose of $0.33 \mathrm{mSv}$ (IQR $0.26-0.39 \mathrm{mSv}$ ). 

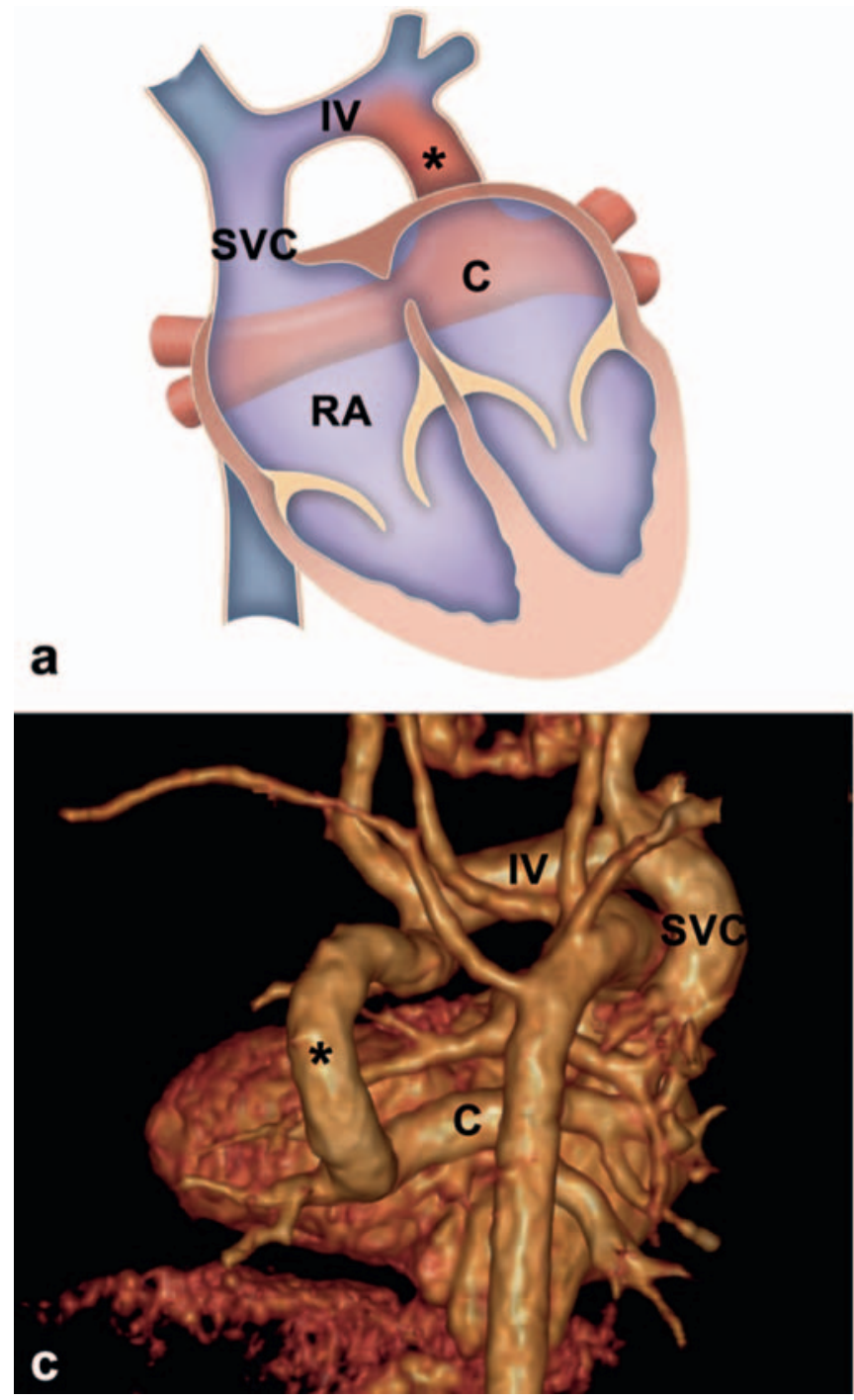
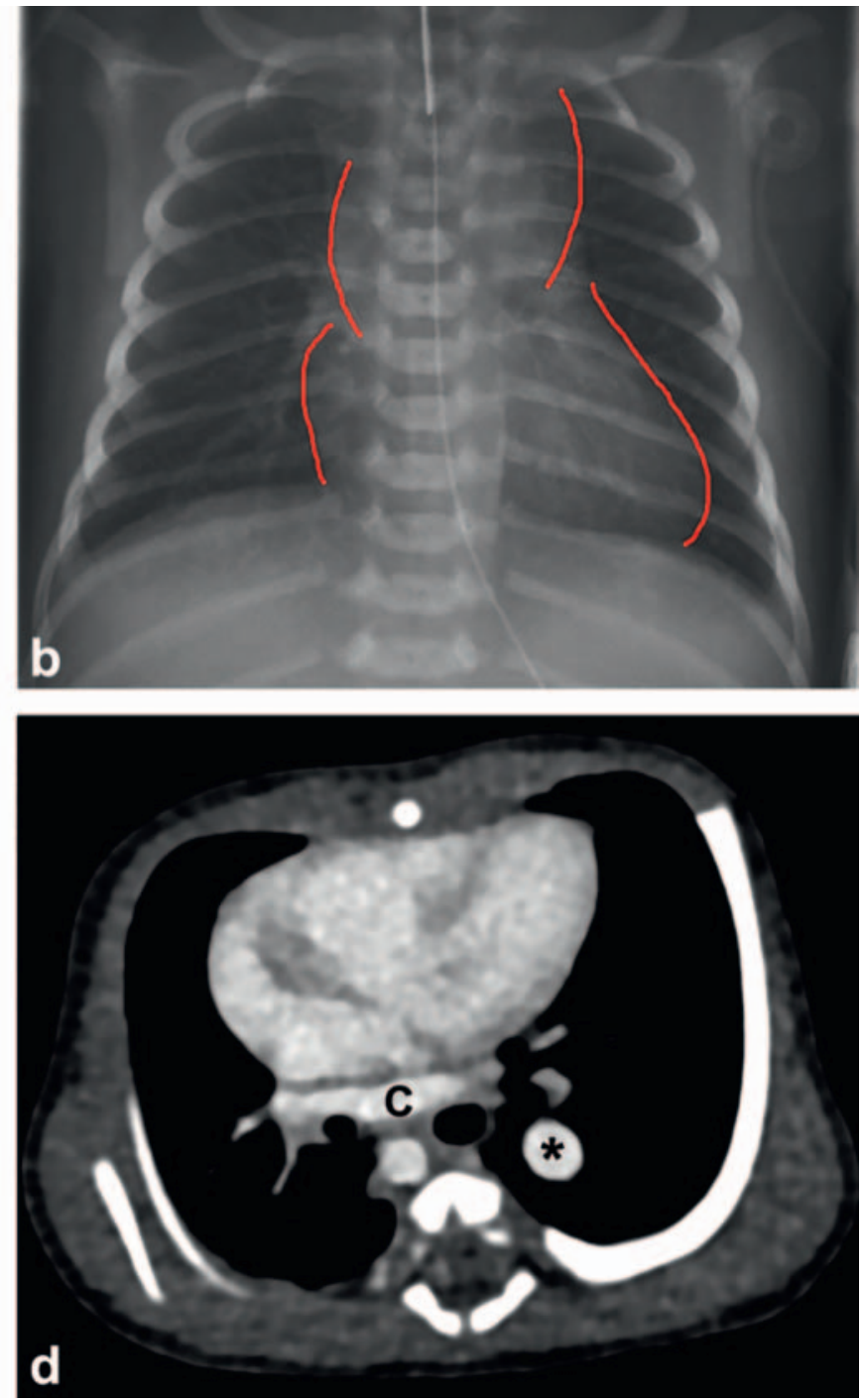

- Fig. 1 Schematic illustration a, chest X-ray b, dorsal view three-dimensional reconstruction c, and transverse CT slice $\mathbf{d}$ of a 5-day-old male infant with the most common type of a supracardiac form of total anomalous pulmonary venous connection: A pulmonary venous collector (C) drains through a vertical vein (asterisk) into the innominate vein (IV) and then via superior vena cava (SVC) into the right atrium (RA). X-ray shows typical snowman configuration (red lines), which is typical for supracardiac total anomalous pulmonary venous connection. Schematic illustration was modified according to Lotz et al. and reprinted with permission [27].

- Abb. 1 Schematische Darstellung a, Röntgenaufnahme des Thorax b, dorsale Ansicht einer 3-dimensionalen Rekonstruktion des Herzens c und transversaler CT-Schnitt $\mathbf{d}$ eines 5 Tage alten männlichen Säuglings mit dem häufigsten Typ der suprakardialen Form einer totalen Lungenvenenfehlmündung: Ein pulmonalvenöses Sammelgefäß (C) drainiert über eine vertikale Vene (Stern) in die Vena anonyma (IV) und dann über die Vena cava superior (SVC) in den rechten Vorhof (RA). Im Röntgenbild ist die typische Schneemann-Konfiguration (rote Linien) zu erkennen, welche für die suprakardiale Form der totalen Lungenvenenfehlmündung typisch ist. Die schematische Darstellung wurde modifiziert aus Lotz et al. [27].

\section{Discussion}

In this study, we demonstrated that APVC can be accurately assessed by high-pitch dual-source CTA in infants with congenital heart defects at a low radiation dose.

High-pitch dual source CTA demonstrated both high levels of sensitivity and specificity in the detection of APVC. This result is consistent with a previous report on the evaluation of pulmonary venous anatomy in adult patients using computed tomography [17]. Similarly, Kim et al. demonstrated that CT angiography allows detection of TAPVC in infants when assessing either axial images or 3D reformations [18]. The availability of comprehensive $3 \mathrm{D}$ reformations is of importance especially in young children with cardiac defects due to the often complex and potentially distorted anatomy which cannot easily be depicted in linear planes. The use of $3 \mathrm{D}$ reformations can improve the planning of surgery and can help to keep the procedure time minimal [19].

Echocardiography remains the routinely applied imaging modality for the evaluation of cardiac defects, especially in young children and newborns, in whom a limited acoustic window is usually not an issue. Previous studies were able to demonstrate that detection of APVC by echocardiography is possible with high 

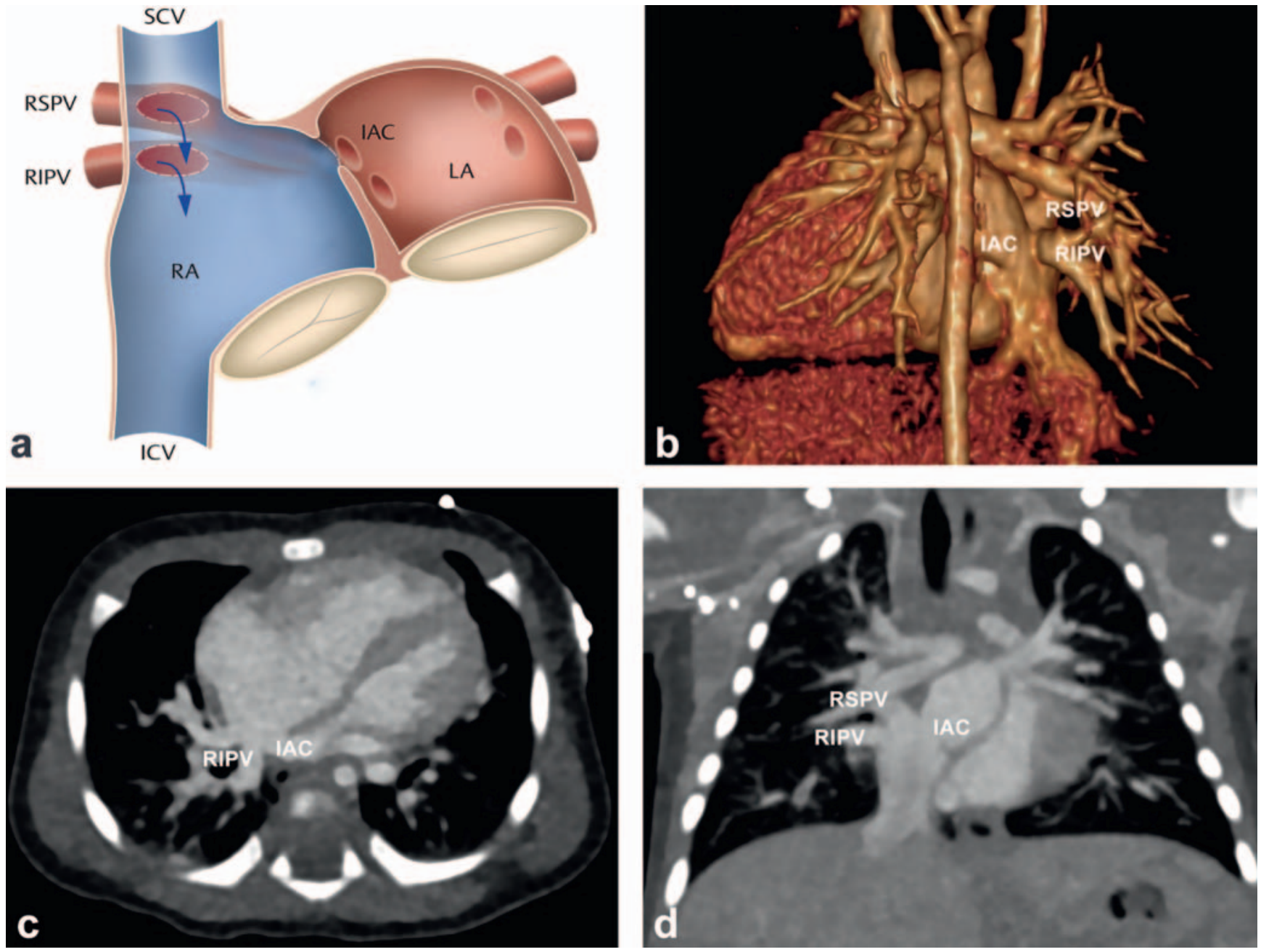

- Fig. 2 Schematic illustration a, dorsal view three-dimensional reconstruction b, transverse CT slice $\mathbf{c}$, and coronal maximum intensity projection with $10 \mathrm{~mm}$ slice thickness $\mathbf{d}$ of a 38-day-old female infant with partial anomalous pulmonary venous connection. Right superior (RSPV) and inferior (RIPV) pulmonary veins drain directly into the right atrium (RA). Note additional interatrial communication (IAC). LA=left atrium; SCV= superior vena cava; ICV = inferior vena cava. Schematic illustration was modified according to Lotz et al. and reprinted with permission [27].

- Abb.2 Schematische Darstellung a, dorsale Ansicht einer 3-dimensionalen Rekonstruktion b, transversaler CT-Schnitt c und koronale Maximumintensitätsprojektion mit einer Schichtdicke von $10 \mathrm{~mm}$ d eines 38 Tage alten weiblichen Säuglings mit partieller Lungenvenenfehlmündung. Rechte obere (RSPV) und rechte untere (RIPV) Lungenvene drainieren direkt in den rechten Vorhof (RA). Zusätzlich besteht eine interatriale Verbindung (IAC). $\mathrm{LA}=$ linker Vorhof; SCV = Vena cava superior; ICV = Vena cava inferior. Die schematische Darstellung wurde modifiziert aus Lotz et al. [27].

diagnostic accuracy and that modern 3D-echocardiography allows for calculation of ventricular volumes in select patients [20-22]. However, in our study CTA allowed for detection of APVC in a higher number of patients compared to echocardiography and correctly identified the anatomy of pulmonary veins in two patients with inconclusive echocardiography results. Similarly, Jiang et al. found that CTA is more sensitive with respect to diagnosing APVC compared to echocardiography, especially in the detection of infracardiac APVC and evaluation of extracardiac structures [7]. Additionally, the capability of comprehensive 3D reformation by echocardiography is limited [23].

Similar to CTA, cardiac MRI allows 3D imaging of CHD and has demonstrated that evaluation of CHD and APVC is feasible with high levels of sensitivity and specificity [24]. Especially freebreathing sequences (e. g. navigator gated steady-state free-pre- cession sequences) have demonstrated good diagnostic accuracy for evaluation of CHD in adults and pediatric patients [25-27]. Additionally, MRI allows measurement of pulmonary and systemic blood flow which offers additional information for therapeutic decision-making. However, limitations of MRI, such as long acquisition times in comparison to CT, susceptibility to artifacts especially in patients with irregular heart rhythm and high cardiac frequencies, and the requirement for general anesthesia in some young pediatric patients have to be considered [27]. Especially in children with complex CHD, intubation and general anesthesia are avoided if possible, due to the usually poor general condition. Therefore, a fast imaging approach without the need for general anesthesia is preferable in select patients.

The radiation dose in our patient cohort was low and comparable to previous studies regarding high-pitch dual-source CTA in 
- Table 1 Patient characteristics.

- Tab. 1 Patientenmerkmale.

\begin{tabular}{|c|c|c|c|c|c|}
\hline patient & age (days) & sex & justifying indication for CT & main diagnosis & $\begin{array}{l}\text { pulmonary vein } \\
\text { drainage }\end{array}$ \\
\hline 1 & 77 & $f$ & pulmonary vascular anatomy & right-sided lung agenesis & regular \\
\hline 2 & 3 & $f$ & TGA, vascular anatomy & TGA & regular \\
\hline 3 & 299 & $\mathrm{~m}$ & coarctation of the aorta & coarctation of the aorta & regular \\
\hline 4 & 38 & $f$ & PAPVC, pulmonary vascular anatomy & PAPVC and sinus venosus defect & PAPVC \\
\hline 5 & 5 & $\mathrm{~m}$ & TAPVC, drainage of pulmonary veins & TAPVC and DORV & TAPVC \\
\hline 6 & 5 & $\mathrm{~m}$ & TGA, vascular anatomy & TGA & regular \\
\hline 7 & 36 & $\mathrm{~m}$ & pulmonary vascular anatomy & pulmonary atresia & regular \\
\hline 8 & 1 & $f$ & TOF, vascular anatomy & TOF and right-sided lung agenesis & regular \\
\hline 9 & 44 & $f$ & configuration of aortic arch & hypoplastic left heart syndrome & regular \\
\hline 10 & 6 & $\mathrm{~m}$ & APVC & double aortic arch & regular \\
\hline 11 & 2 & $\mathrm{~m}$ & drainage of pulmonary veins & hypoplastic left heart syndrome & PAPVC \\
\hline 12 & 3 & $\mathrm{~m}$ & anatomy of extracardiac vessels & TGA and pulmonary atresia & regular \\
\hline 13 & 4 & $\mathrm{~m}$ & TAPVC & TAPVC & TAPVC \\
\hline 14 & 6 & $\mathrm{~m}$ & PAPVC/coarctation of the aorta & PAPVC and coarctation of the aorta & PAPVC \\
\hline 15 & 15 & $f$ & coarctation of the aorta & coarctation of the aorta & regular \\
\hline 16 & 37 & $\mathrm{~m}$ & $\begin{array}{l}\text { coarctation of the aorta and anatomy } \\
\text { of coronary arteries }\end{array}$ & hypoplastic aortic arch & regular \\
\hline 17 & 18 & $\mathrm{~m}$ & TAPVC & TAPVC & TAPVC \\
\hline
\end{tabular}

TGA: transposition of the great vessels; PAPVC: partial anomalous pulmonary venous connection; TAPVC: total anomalous pulmonary venous connection; DORV: double outlet right ventricle; TOF: tetralogy of Fallot.

TGA = Transposition der großen Gefäße; PAPVC = partielle Lungenvenenfehlmündung; TAPVC= totale Lungenvenenfehlmündung; DORV = double outlet right ventricle; TOF = Fallot-Tetralogie.

infants [9]. Especially studies on third-generation dual-source CT units have demonstrated that, with a reduction of tube voltage to $70-\mathrm{kV}$, a high diagnostic accuracy can be maintained while effectively reducing radiation exposure in the evaluation of cardiac defects [9]. It has to be taken into account that the effective radiation doses in our study population are estimates, based on a conversion factor for $80-\mathrm{kV} p$ and that the individual effective dose values might differ slightly. Therefore, comparability to other studies is limited. However, other studies on third-generation dual-source CT units with tube voltages of 70-kV utilized an identical conversion factor with similar results regarding effective radiation dose $[9,14]$. A decrease in tube voltage naturally leads to an increase in image noise due to lower photon flux and beam-hardening artifacts. However, high image quality can be achieved despite low tube voltage by using modern iterative reconstruction algorithms, such as the advanced modeled iterative reconstruction (ADMIRE) used in this study [9]. Importantly, the achievable radiation dose of high-pitch CT for the evaluation of cardiac defects has become lower than that of interventional angiography, increasingly strengthening the role of CT in the diagnostic process of congenital heart defects [10].
Prospectively, high-pitch dual-source CTA will become increasingly important in pediatric cardiology due to the benefits of high spatial resolution, comprehensive 3D rendering, fast image acquisition without the need for general anesthesia and the ability to assess extracardiac structures. This notion is already supported by the "Consensus recommendations of the German Radiology Society (DRG), the German Cardiac Society (DGK), and the German Society for Pediatric Cardiology (DGPK) on the Use of Cardiac Imaging with Computed Tomography and Magnetic Resonance Imaging" [12].

Several limitations of this study have to be taken into account. The reference standard of this study was comprised of a combination of imaging modalities, including the investigated modality itself and only some of the diagnoses were confirmed during surgery. Therefore, the risk of statistical bias was increased. It would have been preferable to include only cases with intraoperatively confirmed diagnoses of APVC. However, this would have further reduced the small number of included patients, which in itself was a limitation of this study. Additionally, the small number of only six patients with APVC within the studied cohort was a limitation. Furthermore, the effective radiation dose values in our study are estimates based on a conversion factor for $80-\mathrm{kV}$ as described 
- Table 2 Sensitivity, specificity, positive predictive value (PPV), and negative predictive value (NPV) with $95 \%$ confidence interval of computed tomography for the detection of anomalous pulmonary vein connection in infants.

- Tab.2 Sensitivität, Spezifität, positiver prädiktiver Wert (PPV) und negativer prädiktiver Wert (NPV) mit $95 \%$-Konfidenzintervall der Computertomografie zur Detektion von Lungenvenenfehlmündungen bei Säuglingen.

\begin{tabular}{|l|l|l|l|}
\hline & rater 1 & rater $\mathbf{2}$ & overall \\
\hline sensitivity & $91 \%(69-98 \%)$ & $91 \%(69-98 \%)$ & $91 \%(77-97 \%)$ \\
\hline specificity & $100 \%(92-100 \%)$ & $98 \%(89-100 \%)$ & $99 \%(94-100 \%)$ \\
\hline PPV & $100 \%(80-100 \%)$ & $95 \%(74-100 \%)$ & $98 \%(86-100 \%)$ \\
\hline NPV & $97 \%(87-100 \%)$ & $97 \%(87-100 \%)$ & $97 \%(91-99 \%)$ \\
\hline
\end{tabular}

above. More precise individual effective dose values might differ from these estimates and would be preferable for risk assessment and comparability. Unfortunately, no dedicated conversion factor for $70-\mathrm{kV}$ has been made available as of yet. However, the actual radiation doses in our study most likely lie below the provided estimated effective dose values due to the fact that conversion factors decrease with reduced tube voltage. Finally, an intraindividual comparison of high-pitch dual-source CTA with state-of-theart cardiac MRI examinations would have been preferable. However, due to the fact that some patients were critically ill, execution of lengthy MRI examinations was not feasible.

\section{Conclusion}

In conclusion, high-pitch CTA in infants with congenital heart defects allows for accurate and reliable assessment of APVC at a low radiation dose. These findings emphasize the increasingly important role of high-pitch CTA in young patients with congenital heart defects.

\section{CLINICAL RELEVANCE OF THE STUDY}

- Third-generation high-pitch dual-source CTA allows detection of an anomalous pulmonary venous connection (APVC) with high levels of sensitivity and reliability and detection of APVC in congenital heart defects is of importance for reliable planning of correction surgery.

- The high-pitch dual-source CTA of infants with congenital heart defects is feasible at low radiation doses.

- The high diagnostic accuracy and low radiation dose make the high-pitch dual-source CTA an increasingly important tool in the treatment of infants with congenital heart defects.

\section{Conflict of Interest}

The authors declare that they have no conflict of interest.

\section{References}

[1] Anderson R, Macartney F. Pulmonary venous abnormalities. In: Paediatr Cardiol 2nd Editio London: Churchill, Livingstone; 2002: 867-899

[2] Hughes C, Rumore P. Anomalous pulmonary veins. Arch Pathol 1944; 37: 364-366

[3] Schultz AH, Localio AR, Clark B] et al. Epidemiologic features of the presentation of critical congenital heart disease: Implications for screening. Pediatrics 2008; 121: 751-757

[4] Tumanyan MR, Filaretova OV, Chechneva VV et al. Repair of complete atrioventricular septal defect in infants with down syndrome: Outcomes and long-term results. Pediatr Cardiol 2015; 36: 71-75

[5] Glöckler M, Halbfaß], Koch A et al. Preoperative assessment of the aortic arch in children younger than 1 year with congenital heart disease: utility of low-dose high-pitch dual-source computed tomography. A singlecentre, retrospective analysis of 62 cases. Eur J Cardiothorac Surg 2014; 45: 1060-1065

[6] Padalino MA, Cavalli G, De Franceschi M et al. Surgical Outcomes of Total Anomalous Pulmonary Venous Connection Repair: A 22-Year Experience. J Card Surg 2014; 29: 678-685

[7] Jiang L, Xie L], Yang ZG et al. Preoperative evaluation of anomalous pulmonary venous connection using dual-source computed tomography: Comparison with echocardiography. Eur J Radiol 2017; 94: 107-114

[8] Slovis TL. Sedation and anesthesia issues in pediatric imaging. Pediatr Radiol 2011; 41 (Suppl. 2): 514-516

[9] Rompel O, Glöckler M, Janka R et al. Third-generation dual-source $70-\mathrm{kVp}$ chest $\mathrm{CT}$ angiography with advanced iterative reconstruction in young children: image quality and radiation dose reduction. Pediatr Radiol 2016; 46: 462-472

[10] Watson TG, Mah E, Joseph Schoepf U et al. Effective radiation dose in computed tomographic angiography of the chest and diagnostic cardiac catheterization in pediatric patients. Pediatr Cardiol 2013; 34: 518-524

[11] Türkvatan A, Tola HT, Kutlutürk N et al. Low-Dose Computed Tomographic Imaging of Partial Anomalous Pulmonary Venous Connection in Children. World J Pediatr Congenit Heart Surg 2017; 8: 590-596

[12] Achenbach S, Barkhausen J, Beer $\mathrm{M}$ et al. Konsensusempfehlungen der DRG/DGK/DGPK zum Einsatz der Herzbildgebung mit Computertomografie und Magnetresonanztomografie. RoFo Fortschritte Auf Dem Gebiet Der Rontgenstrahlen Und Der Bildgeb. Verfahren 2012; 184: 345-368

[13] Deak PD, Smal Y, Kalender WA. Multisection CT protocols: Sex- and age-specific conversion factors used to determine effective dose from dose-length product. Radiology 2010; 257: 158-166

[14] Nau D, Wuest W, Rompel O et al. Evaluation of ventricular septal defects using high pitch computed tomography angiography of the chest in children with complex congenital heart defects below one year of age. J Cardiovasc Comput Tomogr 2019; 13: 226-233

[15] Landis JR, Koch GG. The Measurement of Observer Agreement for Categorical Data. Biometrics 1977; 33: 159

[16] Lotz J, Beerbaum P, Steinmetz M. Partial Pulmonary Venous Anomalies. In: Gutberlet M, (ed.) Diagnostic Imaging Congenit. Hear. Defects Diagnosis Image-Guided Treatmen. 1st Editio Georg Thieme Verlag; 2020: 235-247

[17] Lee HJ, Kim Y], Hur J et al. Low-dose electrocardiography synchronized nonenhanced computed tomography for assessing left atrium and pulmonary veins before radiofrequency catheter ablation for atrial fibrillation. Am J Cardiol 2011; 108: 536-540

[18] Kim TH, Kim YM, Suh CH et al. Helical CT Angiography and ThreeDimensional Reconstruction of Total Anomalous Pulmonary Venous Connections in Neonates and Infants. Am J Roentgenol 2000; 175: $1381-1386$ 
[19] Hammon M, Rompel O, Seuss H et al. Accuracy and Specific Value of Cardiovascular 3D-Models in Pediatric CT-Angiography. Pediatr Cardiol 2017; 38: 1540-1547

[20] Zhang Z, Zhang L, Xie F et al. Echocardiographic diagnosis of anomalous pulmonary venous connections: Experience of 84 cases from 1 medical center. Medicine (Baltimore) 2016; 95: e5389

[21] Gutberlet M, Abdul-Khaliq H, Grothoff $M$ et al. Vergleich der transthorakalen 3D-echokardiographie mit der MRT zur bestimmung linksventrikulärer volumina bei patienten mit pathologischer ventrikelgeometrie aufgrund angeborener herzfehler. RoFo Fortschritte Auf Dem Gebiet Der Rontgenstrahlen Und Der Bildgeb Verfahren 2003; 175: 942-951

[22] Abdul-Khaliq H, Gutberlet M. Technical Basics of Diagnostic and Interventional Imaging - Echocardiography. In: Gutberlet M, (ed.) Diagnostic Imaging Congenit. Hear. Defects Diagnosis Image-Guided Treatmen. $1^{\text {st }}$ Edition Georg Thieme Verlag; 2020: 43-52

[23] Brown VE, De Lange M, Dyar DA et al. Echocardiographic spectrum of supracardiac total anomalous pulmonary venous connection. J Am Soc Echocardiogr 1998; 11: 289-293
[24] Valsangiacomo ER, Levasseur S, McCrindle BW et al. Contrast-enhanced MR angiography of pulmonary venous abnormalities in children. Pediatr Radiol 2003; 33: 92-98

[25] Sørensen TS, Körperich H, Greil GF et al. Operator-independent isotropic three-dimensional magnetic resonance imaging for morphology in congenital heart disease: A validation study. Circulation 2004; 110: 163 169

[26] Fenchel M, Greil GF, Martirosian P et al. Three-dimensional morphological magnetic resonance imaging in infants and children with congenital heart disease. Pediatr Radiol 2006; 36: 1265-1272

[27] Fratz S, Chung T, Greil GF et al. Guidelines and protocols for cardiovascular magnetic resonance in children and adults with congenital heart disease: SCMR expert consensus group on congenital heart disease. J Cardiovasc Magn Reson 2013; 15: 1-26 